\title{
Evaluation of the Developed Formaldehyde Detector
}

\author{
Crystalynne D. Cortez and Jennifer L. Santos
}

\begin{abstract}
The study was an evaluation of the formaldehyde detector that the proponents developed. The purpose of the study was to determine the consistency response of the device to the presence of formaldehyde. Specifically, the study aimed to expose and test the device with three different concentration of formalin. Small scale experimental method was used in the study where the gas sensor was placed inside an eight liter closed container. The gas sensor was exposed with formalin for 5 minutes and without formalin for another 5 minutes. Three different concentration of formalin were used in the experiment which were $1 \%, 5 \%$ and $10 \%$. Three trials for every concentration were conducted. It was found that the device have constant response graphs to the three tests indicating that it was sensitive to formaldehyde of low to high concentrations. Furthermore, the developed formaldehyde detector worked properly within the limits set to it.
\end{abstract}

Index Terms-Gas sensor, consistency response, formalin exposure, formalin testing.

\section{INTRODUCTION}

Formaldehyde which is a colorless flammable gaseous substance with a very strong smell is widely used in number of industries. It is used as an ingredient in manufacturing building materials and making household products; and as preservative in medical laboratories and funeral homes [1]. It is used in making glues, fabrics, plastics, paints, varnishes, carpets, medicines, and beauty aids [2], [3].

Exposure to formaldehyde can be occupational and non-occupational. Some of the workers with highest continuous exposure level (2-5ppm) are those involved in varnishing of furnitures and wooden floors, and in the garment and finishing of textiles industry. There are also jobs that has shorter-term exposure but with high levels (3ppm-higher) like those in production of paper, the pathologists, and the embalmers. On the other hand, there are occupations that have lower levels of exposure such as manufacturing of abrasive and rubber, and formaldehyde production industries. Sources of non-occupatinal exposures include cigarette smoke, paint, varnish, plastic, carpet, and vehicle emissions [4].

Being an active component in many household products, formaldehyde is also considered as a hazardous chemical. According to National Institute for Occupational Safety Health, formaldehyde is a suffocating gas that can cause eyes, nose, throat, and respiratory system irritation. It was even considered as a potential occupational carcinogen. The

Manuscript received May 29, 2015; revised August 6, 2015

The authors are with the Computer Education Department, Centro Escolar University, Manila, Philippines (e-mail: cdcortez@ceu.edu.ph, jlsantos@ceu.edu.ph). exposure limit set by Occupational Safety and Health Administration to formaldehyde was $0.75 \mathrm{ppm}$ measured as an 8-hour time-weighted average (TWA) and $2 \mathrm{ppm}$ short-term exposure limit (STEL) allowed during a 15-minute period [5].

Nausea, headache, tear overflow and burning sensation in the throat were the immediate effects to people exposed to high concentration of formaldehyde. However, contact dermatitis, congenital defects, and cancer were results of long-term exposure to formaldehyde [6]. The effects of formaldehyde on human vary on the concentration level of exposure: $0.05-1.05 \mathrm{ppm}$ could lead to neurophysiologic effect; $0.05-1.0 \mathrm{ppm}$ was considered the respiration air threshold; 0.05-2.0 ppm could cause ocular irritation; 0.1-2.5 ppm could cause upper respiratory tract irritation; $5.0-30 \mathrm{ppm}$ had severe effects on the lungs and lower respiratory tract; 50-100 ppm could cause pneumonia and pulmonary edema; and $\geq 100 \mathrm{ppm}$ could lead to death [7].

Exposure to formaldehyde can be classified as indoor, and outdoor exposures. According to the World Health Organization (WHO), most cases of FA exposure happens indoor. In 2010, an indoor air guideline value was developed by WHO to prevent upper respiratory and eye irritation, and as much as possible, cancer. The guideline stated that the maximum daily exposure to $0.1 \mathrm{mg} / \mathrm{m} 3$ of formaldehyde is 30 minutes [8].

There was a study made in Taiwan wherein risk assessment of formaldehyde in typical office buildings was done. The result showed that there were also high levels of formaldehyde in non-industrial environments [9]. This contradicted the result of most studies that proved that high concentrations of formaldehyde were found in manufacturing, funeral homes, and laboratories.

Since formaldehyde is present in most products that people use, it is important to know the level of formaldehyde present in air in order to avoid its symptoms and hazardous effects. To do this, formaldehyde detectors were used. Cortez et al. (2015) developed a low-cost prototype of a formaldehyde detector that could detect formaldehyde levels in ppm [10]. This detector was evaluated in the study.

\section{OBJECTIVES}

The study aimed to evaluate the developed formaldehyde detector to determine its consistency response to the presence of formaldehyde. Specifically, it aimed to expose and test the device with three different concentration of formalin.

\section{Methodology}

Small scale experimental analysis was used in the study to evaluate the ability of the device to sense formaldehyde. Test 
set-up was shown in Fig. 1 where the formaldehyde gas sensor was placed in an 8 liter closed container.

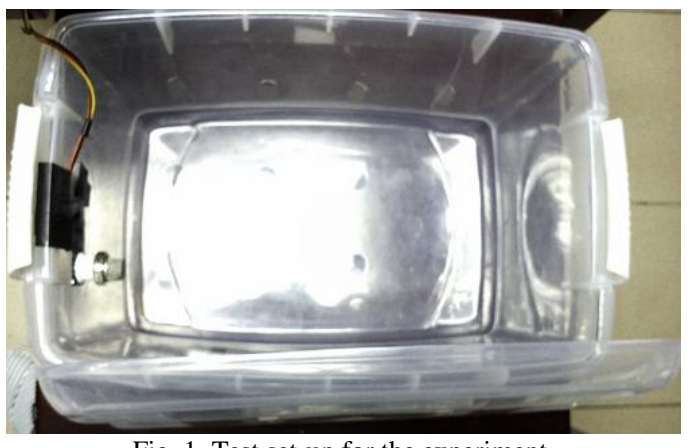

Fig. 1. Test set-up for the experiment.

Once the reading inside the container was stable, $50 \mathrm{ml}$. of formalin was introduced inside the container as shown in Fig. 2.

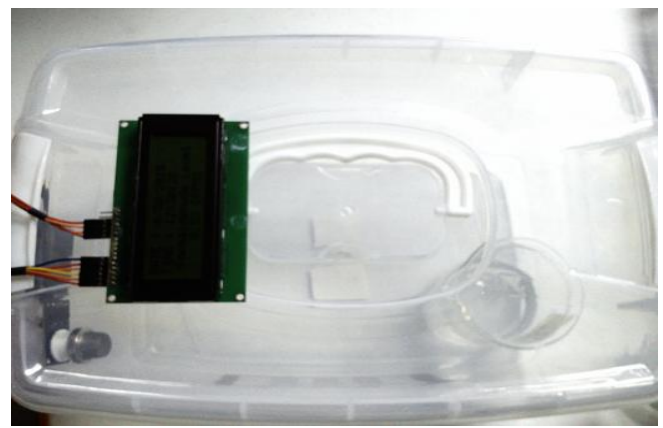

Fig. 2. Test set-up where $50 \mathrm{ml}$. of formalin placed inside the container.

The gas sensor was exposed with formalin for 5 minutes to let the particles of formaldehyde evaporate and diffuse in the container. The formalin was then removed from the container and the gas sensor was exposed for another 5 minutes. 600 samples of formaldehyde gas concentration was taken from the test.

Three different concentration of formalin were used in the experiment as shown in Fig. 3. These were 1\%, 5\% and $10 \%$. Three trials for every concentration were conducted to examine the consistency of the device to sense formaldehyde. The tests were done in different day and time.

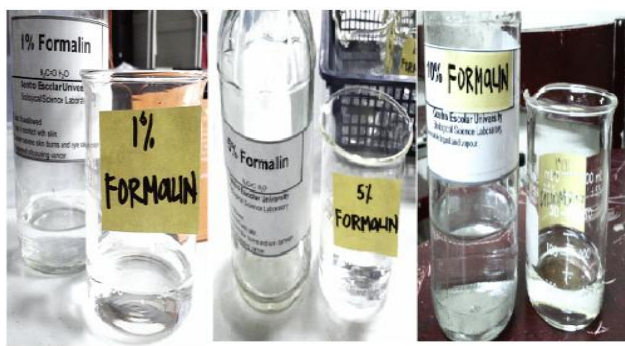

Fig. 3. Different test concentrations of formalin.

\section{RESUlTS AND DISCUSSION}

Formaldehyde detector is a low cost gas detector that was developed by the proponents to detect any presence of formaldehyde in the environment. The purpose of the detector was to notify the user of the formaldehyde concentration in parts per million (ppm) as unit of measurement for formaldehyde gas concentration.

According to Bolmen (1998), basic gas detection principle was comprised of five functional components. These were transport of air sample, analysis of air sample, identification of target gas concentration, comparison of concentration to alarm set points and actions to alarm conditions [11]. During the transport, air in the monitored environment was collected using the sorption process. These collected samples was next analyzed by the gas sensor using the gas detection principle and techniques to determine if a specific target gas was present in the air sample [12]. Once the gas concentration of the target gas was identified, comparison to alarm set points was done. These principles were carried out to the design of the detector. The set points for the detector was based from OSHA 2 ppm short-term exposure limit.

The principle of the actual formaldehyde detector prototype was shown in Fig. 4. Air samples in the environment was absorbed by the gas sensor. The resistivity of the gas sensor with respect to formaldehyde particles was then transmitted to the microcontroller unit where it was processed and converted into parts per million. The reading was then displayed to the liquid crystal display (LCD). Real time data per second, recorded by the device, was saved in the secure digital card (SD) added in the design. The data saved were imported for analysis.

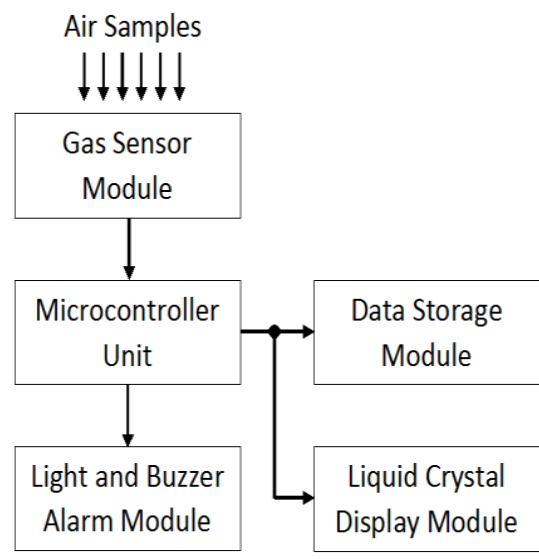

Fig. 4. Block diagram of the low-cost developed prototype of formaldehyde detector.

Gas sensor was the key component of the detector, which was defined as a transducer that detects gas molecules and which produces an electrical signal with a magnitude proportional to the concentration of the gas [13]. Selectivity of the formaldehyde sensor was taken into account. Selectivity of the gas sensor indicated the extent to which it can determine a particular analyte of formaldehyde without interferences from other components of the sample [12].

As a rule, gas sensor was used to carry out sequential analysis of series of samples. The response time of the sensor determine the throughput of the system. The response time was the time elapsed since gas was added to the environment until the sensor response attains a practically constant value. According to Banica (2012), response time of below 1 minute is excellent and a response time of about 10 minutes is still satisfactory [12].

To determine the response of the device to formaldehyde, three tests of different formalin concentration were performed. The first test conducted was using the $1 \%$ formalin. Fig. 5 shows the actual data saved by the device in the SD card for this test. During trial 1 , the initial concentration of 
formaldehyde was recorded in $0.35 \mathrm{ppm}$; during trial 2 , it was $0.46 \mathrm{ppm}$ and during trial 3 , it was $0.53 \mathrm{ppm}$. The differences with the initial values of the three trials was due to the initial calibration of the gas sensor in the environment. Factors such as the presence of other materials containing formaldehyde and the air quality during the time of testing caused the discrepancy of the calibration. Trial 1 was done on May 2, 2015 at 5:20 PM, while trials 2 and 3 were done on May 5, 2015 at 11:16 AM and 12:06 PM respectively. 10 minutes of data collection was performed for the three trials.

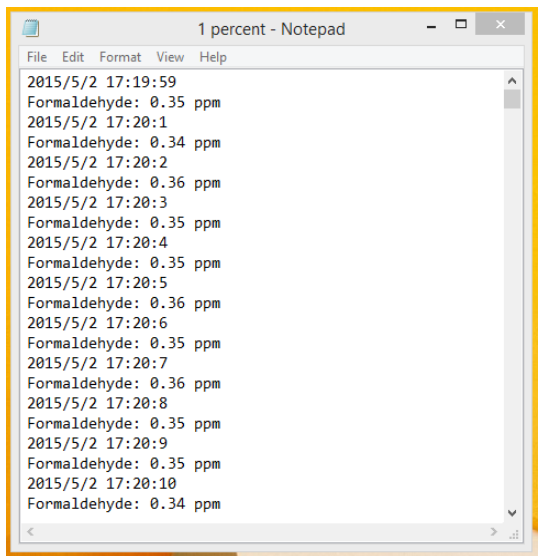

Fig. 5. Actual formaldehyde concentrations recorded by the formaldehyde detector that was saved in the SD card for $1 \%$ formalin.

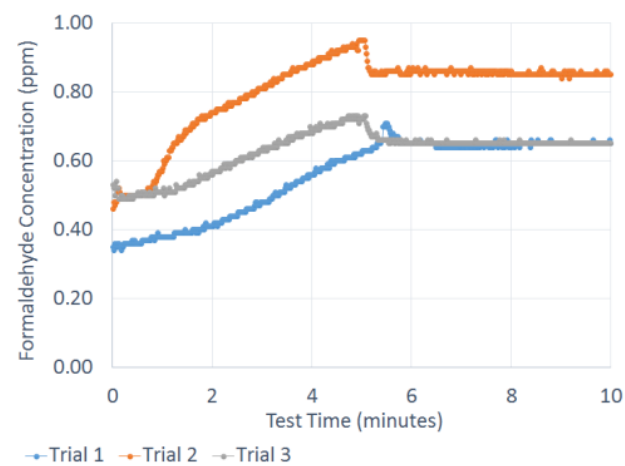

Fig. 6. Test results of the formaldehyde concentration detected by the formaldehyde detector as it was exposed to $1 \%$ formalin.

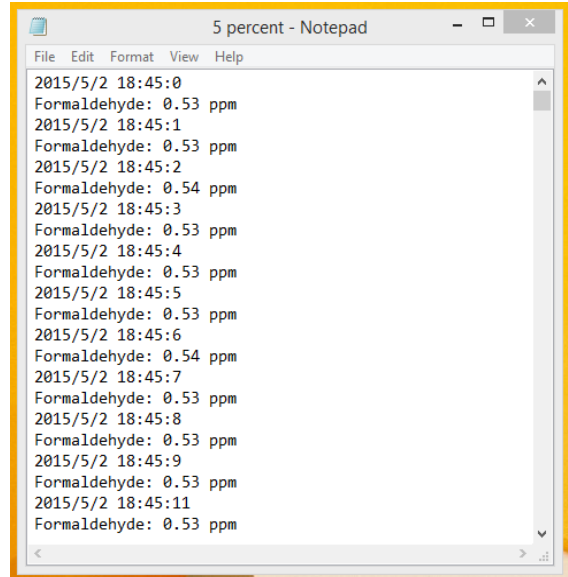

Fig. 7. Actual formaldehyde concentrations recorded by the formaldehyde detector that was saved in the SD card for 5\% formalin.

Fig. 6 shows the response graph of the device for $1 \%$ formalin. Concentration increased drastically as the device was exposed longer with formalin. The peak concentration for trial 1 was recorded at $0.60 \mathrm{ppm}$, for trial 2 at $0.92 \mathrm{ppm}$, and for trial 3 at $0.71 \mathrm{ppm}$. A slight decrease after 5 minutes was recorded. This was the time the formalin was removed from the container. However, the reading stabilized and the device recorded constant formaldehyde concentration until the tenth minute. Average concentration of $0.65 \mathrm{ppm}, 0.85 \mathrm{ppm}$ and $0.65 \mathrm{ppm}$ were noted for trials 1,2 and 3 .

The second test conducted was using the 5\% formalin. Fig. 7 shows the actual data saved by the device in the SD card for this test. During trial 1 , the initial concentration of formaldehyde was recorded in $0.53 \mathrm{ppm}$; during trial 2 , it was $0.57 \mathrm{ppm}$ and during trial 3, it was $0.50 \mathrm{ppm}$. Trial 1 was done on May 2, 2015 at 6:45 PM. While trials 2 and 3 were done on May 5, 2015 at 1:07 PM and 1:24 PM respectively. Data were collected for 10 minutes in every trial.

Fig. 8 shows the response graph of the device for $5 \%$ formalin. Similar with the first test, concentration of formaldehyde in the container increased as the device was exposed longer with formalin. After 5 minutes of exposure, the peak concentration for trial 1 was recorded at $1.25 \mathrm{ppm}$, for trial 2 at $1.43 \mathrm{ppm}$, and for trial 3 at $0.96 \mathrm{ppm}$. Like in test 1 , a slight decrease after 5 minutes was recorded due to the removal of formalin from the container. The reading stabilized and the device recorded constant formaldehyde concentration. Repeatability of values were observed during the $5^{\text {th }}$ to $10^{\text {th }}$ minute of test time. Average concentration of $1.24 \mathrm{ppm}, 1.12 \mathrm{ppm}$ and $0.81 \mathrm{ppm}$ were noted for trials 1,2 and 3.

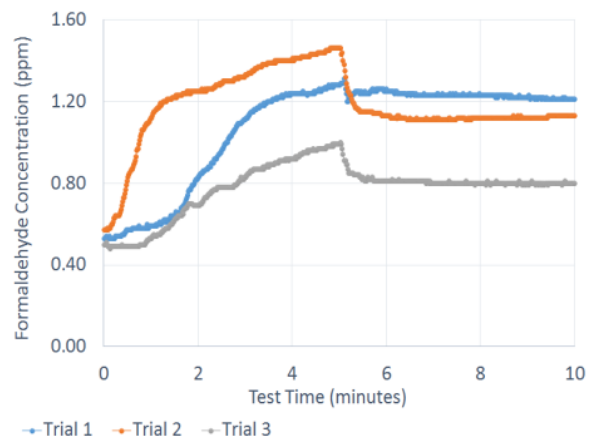

Fig. 8. Test results of the formaldehyde concentration detected by the formaldehyde detector as it was exposed to $5 \%$ formalin.

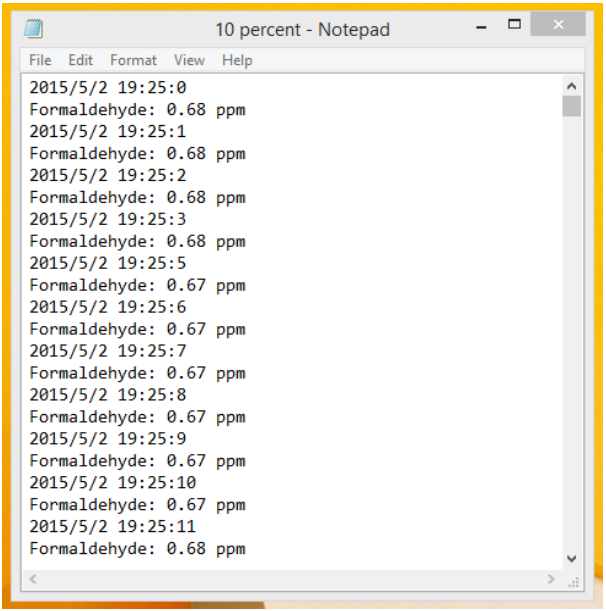

Fig. 9. Actual formaldehyde concentrations recorded by the formaldehyde detector that was saved in the SD card for $10 \%$ formalin.

The last test conducted was using the $10 \%$ formalin. Fig. 9 shows the actual data saved by the device in the SD card These data were imported for analysis. During trial 1 , the initial concentration of formaldehyde was recorded in 0.68 
ppm; during trial 2, it was $0.45 \mathrm{ppm}$ and during trial 3, it was 0.44 ppm. Trial 1 was done on May 2, 2015 at 7:25 PM. While trials 2 and 3 were done on May 5, 2015 at 1:38 PM and 2:07 PM respectively. 10 minutes of data collection was for the three trials.

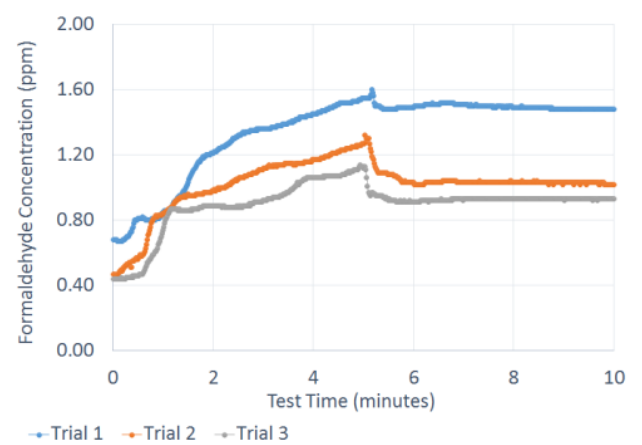

Fig. 10. Test results of the formaldehyde concentration detected by the formaldehyde detector as it was exposed to $10 \%$ formalin.

Fig. 10 shows the response graph of the device for $10 \%$ formalin. Like tests 1 and 2, concentration of formaldehyde in the container increases as the device was exposed with formalin for 5 minutes. The maximum concentration for trial 1 was recorded at $1.51 \mathrm{ppm}$, for trial 2 at $1.22 \mathrm{ppm}$, and for trial 3 at $1.10 \mathrm{ppm}$. Similarly, a slight decrease was recorded upon removal of formalin from the container. The reading became consistent for the last 5 minutes test time. Repeatability of values were also observed. Average concentration of $1.49 \mathrm{ppm}, 1.03 \mathrm{ppm}$ and $0.93 \mathrm{ppm}$ were noted for trials 1,2 and 3 .

\section{CONCLUSIONS}

The developed formaldehyde detector demonstrated to have constant response graphs to the three tests indicating that it was sensitive to formaldehyde of low to high concentrations. It worked properly within the limits set to it. Spontaneity of the detector in recording samples was obtained. It was able to record different concentration levels of different samples. The detector was able to select the particulate of formaldehyde immediately within an elapsed time of less than a minute, thus, giving a direct proportionality between response time and concentration. As gas particles of formalin disperse in the test environment longer, the concentration of formaldehyde increases. The detector exhibited constancy in concentration value a minute after the sample was taken out of the test environment indicating that sensor response was acceptable.

\section{ACKNOWLEDGMENT}

The proponents would like to acknowledge the Research and Evaluation Office of Centro Escolar University for funding the conference presentation and publication of the study; Ms. Angelica Pobocan for providing the different concentration of formalin; and Mr. Leonardo Magtoto for his suggestion on data treatment.

\section{REFERENCES}

[1] EMSL Analytical, Inc. (2015). Formaldehyde testing lab. [Online]. Available:

http://www.formaldehydetesting.com/whatisformaldehyde.html
[2] J. A. Swenberg, B. C. Moeller, K. Lu, J. E. Rager, R. C. Fry, and T. B. Starr, "Formaldehyde carcinogenicity research: 30 years and counting for mode of action, epidemiology, and cancer risk assessment," Toxicologic Pathology, vol. 41, no. 2, pp. 181-189, February 2013.

[3] H. Checkoway, P. Boffetta, D. J. Mundt, and K. A. Mundt, "Critical review and synthesis of the epidemiologic evidence on formaldehyde exposure and risk of leukemia and other lymphohematopoietic malignancies," Cancer Causes and Control, vol. 23, no. 11, pp. 1747-1766, November 2012.

[4] IARC Monographs on the Evaluation of Carcinogenic Risks to Humans, International Agency for Research on Cancer, vol. 88, France, 2006.

[5] Centers for Disease Control and Prevention. (February 13, 2015). NIOSH Pocket Guide to Chemical Hazards. [Online]. Available: http://www.cdc.gov/niosh/npg/npgd0293.html

[6] D. S. Raja and B. Sultana, "Potential health hazards for students exposed to formaldehyde in the gross anatomy laboratory," National Environmental Health Association, May 2011.

[7] M. Incil, I. Zararsiz, M. Davarcil, and S. Gorurl, "Toxic effects of formaldehyde on the urinary system," Turkish Journal of Urology, vol. 39, no. 1, pp. 48-52, March 2013.

[8] G. D. Nielsen, S. T. Larsen, and P. Wolkoff, "Recent trend in risk assessment of formaldehyde exposures from indoor air," Archives of Toxicology, vol. 87, no. 1, pp. 73-98, January 2013.

[9] P. C. Wu, Y. Y. Li, C. C. Lee, C. M. Chiang, and H. J. Su, "Risk assessment of formaldehyde in typical office buildings in Taiwan," International Journal of Indoor Environment and Health, vol. 13, no. 4, pp. 359-363, 2003.

[10] C. D. Cortez, F. C. Bato, T. G. Bautista, J. G. Cantor, C. L. Gandionco, and S. P. Reyes, "Development of formaldehyde detector," International Journal of Information and Electronics Engineering, vol. 5, no. 5, pp. 385-389, September 2015.

[11] R. A. Bolmen, Semiconductor Safety Handbook: Safety and Health in Semiconductor Industry, New Jersey: Noyes Publications, 1998, p. 587.

[12] F. G. Banica, Chemical Sensors and Biosensors: Fundamentals and Applications, United Kingdom: John Wiley \& Sons, 2012, p. 4, 10-11 and 588 .

[13] J. Chou, Hazardous Gas Monitors: A Practical Guide to Selection, Operation and Applications, NY: McGraw Hill Book Co., 1999, p. 3.

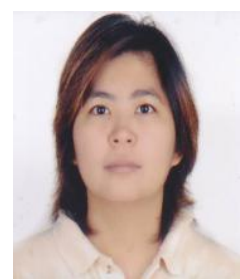

Crystalynne D. Cortez was born on September 10, 1985. She obtained her master of science in electrical engineering in Technological University of the Philippines in April, 2014. She graduated with the bachelor of science in electronics and communications engineering at University of the City of Manila in April, 2006. She also completed the 18 units of professional education.

She is an assistant professor. She serves as a full-time faculty member of Computer Education Department of Centro Escolar University (CEU), Manila, Philippines from 2009 until present, handling professional and research subjects in computer engineering, computer science and information technology courses. Her recent paper publications are entitled "Validation of the developed multi-Gas monitoring system," Periodical on Applied Mechanics and Materials, vol. 666, pp. 245-250, October 2014, etc. Her major fields of researches are microcontroller projects, environmental engineering and biosensors.

Engr. Cortez is a member of IACSIT since May, 2014, IACT since December, 2014 and Institute of Electronics and Communications Engineers of the Philippines.

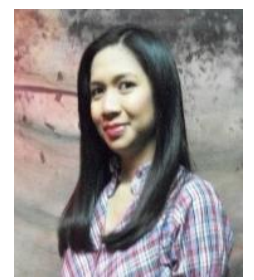

Jennifer L. Santos was born on August 6, 1980. She obtained her masters in information technology in Centro Escolar University in March 2012 and her master of arts in education in major in mathematics education in New Era University in March 2005. She graduated with the bachelor of science in computer engineering at University of the East (Caloocan Campus) in April, 2001.

She is an assistant professor. She serves as a full-time faculty member of Computer Education Department of Centro Escolar University (CEU), Manila, Philippines from 2003 until present, handling professional and research subjects in computer engineering, computer science and information technology courses.

Engr. Santos is a member of IACSIT since July 2014 and of Philippine Society for Educational Research and Evaluation, Inc. 